\title{
Partitioning of Large and Small Airway Resistance in Human Measured by an Anterograde Catheter with a Tip Micromanometer
}

Short Report

\author{
Tamotsu Takishima, Masaru Yanai, Kiyohisa \\ Sekizawa, Takashr Ohrut, Hidetada Sasaki, Masao \\ TaKaHashi* and Hideo Ozawa* \\ The First Department of Internal Medicine, Tohoku \\ University School of Medicine, Sendai 980 and ${ }^{*}$ Nithon \\ Koden Corporation, Tokyo 161
}

\begin{abstract}
Takishima, T., Yanal, M., Sekizawa, K., Ohrui, T., Sasaki, H., Takahashi, M. and Ozawa, H. Partitioning of Large and Small Airway Resistance in Human Measured by an Anterograde Catheter with a Tip Micromanometer. Tohoku J. exp. Med., 1988, 156 (1), 99-100 — We measured lateral pressure in airways 3 $\mathrm{mm}$ in internal diameter in three normal subjects using an anterograde catheter with a tip micromanometer. The pressure was used to partition total pulmonary resistance into a large airway resistance component between the mouth and the pressure sensor and a small airway resistance component between the pressure sensor and alveoli. Large airway resistance and small airway resistance during inspiration were $2.3 \pm 0.4$ and $0.9 \pm 0.2 \mathrm{cmH}_{2} \mathrm{O} / \mathrm{liter} / \mathrm{sec}$ (mean \pm s.E.), respectively, and small airway resistance was $29 \%$ of the total pulmonary resistance. We suggest that the present technique may be useful for determining the localization of airway resistance in human subjects. ___ bronchial pressure; pulmonary resistance; catheter tip micromanometer
\end{abstract}

To study the mechanisms responsible for pathophysiological changes in chronic obstructuve pulmonary disease (COPD), the site and nature of airway obstruction have been extensively studied. However, a direct measurement of small airway resistance is difficult because of the problem of designing a catheter with an adequate dynamic response yet small enough to measure pressures in small airways. Macklem and Mead (1967) overcame this problem by developing a retrograde catheter technique. Subsequently, several investigators have found that the major site of resistance in normal lungs is in the large airway, yet the small airways are the major site of resistance in COPD (Hogg et al. 1968). However, the retrograde catheter can be applied only on animals and excised human lungs. By using a catheter tip micromanometer, we report here successful measurement of small airway pressures which allowed us to partition resistance between the large and small airways in living human subjects.

Lateral pressure in airways $3 \mathrm{~mm}$ in internal diameter was measured using a catheter

Received June 29, 1988; revision accepted for publication August 30, 1988.

Correspondence: T. Takishima, M.D., the First Department of Internal Medicine, Tohoku University School of Medicine, Sendai 980, Japan. 
A

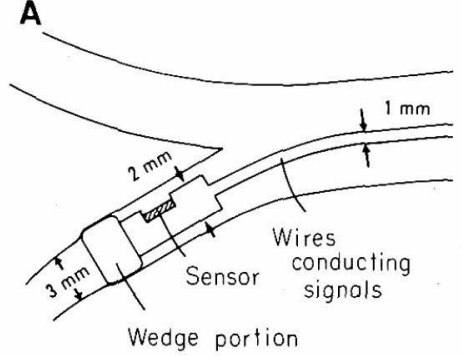

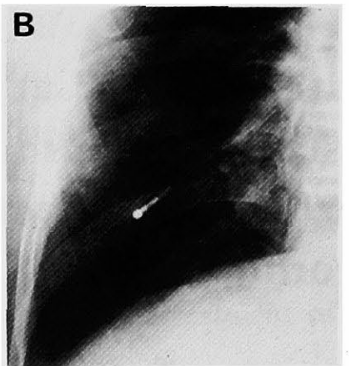

Fig. 1. A : Structure of the catheter tip micromanometer.

B : Chest roentogenogram which shows the actual location of the catheter tip micromanometer in the airway.

with a tip micromanometer (experimentally manufactured by Nihon Kohden Co., Tokyo) as shown in Fig. 1A. The catheter consists of three parts; a hemispherical tip $3 \mathrm{~mm}$ in diameter, an oblong diaphragm pressure sensor $(1 \times 2 \mathrm{~mm}$; semiconductor strain gauge $) 3$ $\mathrm{mm}$ proximal from the tip, and thin teflon covered wires ( $1 \mathrm{~mm}$ in outer diameter) conducting electrical signals to an amplifier. The transducer system has a $90 \%$ response within 20 msec and is linear between 0 to $300 \mathrm{cmH}_{2} \mathrm{O}$. In preliminary studies, we measured pressures in $3 \mathrm{~mm}$ internal diameter airways of excised dog lungs simultaneously, by both the retrograde catheter and the catheter tip micromanometer methods. Pressures measured by the catheter tip micromanometer were close to those measured by the retrograde catheter at various tidal volume ventilations $(r=0.98, p<0.01)$.

We studied three normal subjects (aged 36 to 57 years). All of them were non-smokers and had normal pulmonary function tests. To prevent nausea and to provide an adequate sedation, we administered metoclopramide $(10 \mathrm{mg})$ and pentasocin $(15 \mathrm{mg})$ intramuscularily $15 \mathrm{~min}$ before the examination. Under careful observation using an $\mathrm{x}$-ray $\mathrm{TV}$, the catheter was introduced to the right lower lobe bronchus $\left(\mathrm{B}^{9} ; \mathrm{R}\right.$. laterobasalis) through a fiberoptic bronchoscope until the tip was wedged, and then the bronchoscope was removed (Fig. 1B). Simultaneously, we measured mouth flow, mouth pressure and transpulmonary pressure by the esophageal balloon technique during tidal breathing. Total pulmonary resistance was calculated from transpulmonary pressure and mouth flow by the method of Mead and Whittenberger, and large airway resistance from intraairway lateral pressure changes and mouth flow. Small airway resistance (resistance from $3 \mathrm{~mm}$ internal diameter bronchi to alveoli) was obtained by subtraction of large airway resistance from total pulmonary resistance. Inspiratory and expiratory resistances were measured at mid-tidal volume and an average of 10 breaths was used for analysis. Large airway resistance and small airway resistance during inspiration were $2.3 \pm 0.4$ and $0.9 \pm 0.2 \mathrm{cmH}_{2} \mathrm{O} /$ liter/sec (mean \pm s.e.), and during expiration were $2.3 \pm 0.2$ and $1.6 \pm 0.3 \mathrm{cmH}_{2} \mathrm{O} / \mathrm{liter} / \mathrm{sec}$ (mean \pm s.E.), respectively. Small airway resistance was $29 \%$ of total pulmonary resistance during inspiration and $41 \%$ during expiration. Our results were compatible with data obtained by the retrograde catheter technique in animal studies and in excised normal human lungs.

We suggest that this technique of measuring small airway pressure provides useful and significant information on the localization of airway resistance in human subjects, and hopefully in patients with COPD.

\section{References}

1) Hogg, J.C, Macklem, P.T. \& Thurlbeck, W.M. (1968) Site and nature of airway obstruction in chronic obstructive lung disease. New Engl. J. Med., 278, 13551360 .

2) Macklem, P.T. \& Mead, J. (1967) Resistance of central and peripheral airways measured by a retrograde catheter. J. appl. Physiol., 22, 395-401. 